\author{
$\mathrm{Fe}-\mathrm{Co}$ 기 고인성 고강도강의 반복 열처리 거동 - \\ Part 1. 조직제어 \\ 윤보희 • 박경태 * • 이태혁 • 김재 훈 ** • 김홍규 *** • 이성 *** • 이종현 *广 \\ 충남대학교 신소재공학과, *충남대학교 녹색에너지기술전문대학원, **충남대학교 기계설계공학과, ***한국국방과학연구소
}

\title{
The Repeat Heat Treatment Behavior of Double Remelted Fe-Co Ultra-high Strength Steel.- Part. 1 Microstructure Control
}

\author{
Bo-Hee Yoon, Kyoung-Tae Park*, Tae-Hyuk Lee, Jae-Hoon Kim**, \\ Hong-Kyu Kim***, Seong Lee***, and Jong-Hyeon, Lee*广 \\ Department of advanced material engineering, Chungnam national university, Daejeon 305-764, Korea \\ ${ }^{*}$ Graduate school of green energy technology, Chungnam national university, Daejeon 305-764, Korea \\ **Department of mechanical engineering design, Chungnam national university, Daejeon 305-764, Korea \\ ***Agency for defense development of Korea Daejeon 305-600, Korea
}

\begin{abstract}
In this study, microstructural evaluation was carried out on secondary hardening type ultrahigh strength steel, Fe-Co-Ni composition. This paper as a first part of whole research presented the microstructural behavior by cyclic heat treatment. The cyclic heat treatment method includes normalizing, stress relieving, solution treatment and aging. Especially, solution treatments performed triple times to get maximized solution hardening. Phase transformation and microstructure were observed by using optical microscope $(\mathrm{OM})$, Electron back-scattered diffraction (EBSD) and X-ray stress analyzer. During the triple solution treatment, size of grain boundary was dramatically decreased by generating a packet from the martensite transformation of residual austenite in the inner part of grain, whereas the hardness increase was not significant.
\end{abstract}

Key words : Ultra high strength steel, Fe-Co-Ni, Microstructure.

(Received November 21, 2011 ; Accepted February 10, 2012)

\section{1. 서 론}

Ultrahigh-strength steel에 대한 연구는 1960년대부터 지금까지 많은 연구가 진행 되어 왔다. 일반적으로 $1380 \mathrm{Mpa}(200 \mathrm{Ksi})$ 이상인 재료를 ultrahigh-strength steel (UHS)이라하며 UHS는 넓게 3 가지 분류가 가능하다. 분류 내용은 $18 \mathrm{wt} \% \mathrm{Ni}$ 을 함유하 는 마레이징강, $\mathrm{AF} 1410$ 으로 분리 되는 2차경화형 고합금강, AISI4340으로 분리되는 저합금강이다[1]. 현재 UHS 합금 중 가장 높은 특성을 나타내는 것은 2차경화형 고합금강으로 보고 되고 있다. 그 중 $\mathrm{Fe}-\mathrm{Co}-\mathrm{Ni}$ 기 철계 합금으로 대변되는 2차경화 형 UHS는 $\mathrm{Mo}, \mathrm{V}$ 등의 합금원소가 첨가된 재료로서 90 년대 초반에 미국의 Carpenter Technology Corp.에서 Aermet100라

Corresponding author: Jong-Hyeon Lee

[Tel: +82-42-821-6596, E-mail : jonglee@cnu.ac.kr]
는 상품명으로 개발된 합금이 대표적이며 기계적 특성은 $1750 \mathrm{Mpa}$ 정도의 항복강도와 $170 \mathrm{Mpa} \cdot \mathrm{M}^{1 / 2}$ 의 파괴인성을 가지 고 있다. 본 2차경화형 $\mathrm{UHS}$ 는 마레이징강에 비해서 강도는 비슷한 수준을 유지하면서 파괴인성측면에서는 상당히 높은 특 성을 나타내기에 Jet engine shaft나 비행기의 착륙기어, 장갑 재료, 고온재료 등에 사용되고 있으며, 그 수요는 갈수록 증가 하는 추세이다[1,2]. 경화 기구는 [Mo.Co.V $]_{2} \mathrm{C}$ 에 형성에 의한 분산강화 현상과 그에 따른 전위밀도 증가와, 오스테나이트 안 정화 원소인 $\mathrm{Ni}$ 함량에 따른 $\mathrm{AC}_{1}$ 선 변화에 의해 결정된다고 보고 되고 있다[3].

강성과 인성을 동시에 요구하는 ultrahigh-strength steel에서 는 강의 품질을 개선하기 위한 고청정용해법을 이용한 특성향상 
과 함께 다양한 열처리를 통한 미세조직제어가 반드시 수반되어 야 한다. M. J. Yokota 등이 발표된 연구를 참조하면 철계 합 금에서 열처리에 따라 조직내부에 존재하는 Lath martensite/ austenite 형상, 분율, 크기, 간격 등을 제어 할 수 있다는 보 고가 있고, 이를 통해 열처리 시 발생하는 조직 내부에 여러 인자들이 파괴인성 및 강도 증가 측면에서 많은 영향을 주고 있음을 알 수 있다[4]. 결정립도 제어를 위하여 반복적인 용체 화 처리를 통해 packet 형성을 극대화 할 수 있으며, 또한 이 렇게 형성된 packet은 조직 내에서 결정립과 같은 역할로서 Hall-Petch이론과 Griffith 이론에 따라 강성과 인성부가에 많은 영향을 끼친다[6,7,8].

따라서 본 논문에서는 $\mathrm{Fe}-\mathrm{Co}-\mathrm{Ni}$ 기 Ultrahigh Strength Steel 에 대하여 normalizing, stress relieving, solution treatment, aging 등 다양한 열처리방법과 반복적 용체화 처리에 따른 따 른 미세조직개량 변화에 초점을 맞추어 실험을 진행하였으며, 경도변화측정을 통한 인성유추 실험을 병행하였다.

\section{2. 실험 방법}

\section{1 사용재료 및 열처리}

실험에 사용된 재료는 $\mathrm{Fe}-\mathrm{Co}-\mathrm{Ni}$ 기 UHS 합금으로 자세한 성분표는 Table 1에 나타내었으며 고주파 유도로에서 용해 후 정련을 위하여 Electro slag remelting 공법으로 정련 후 추가적 으로 Vacuum arc remelting을 다시 실시하여 합금 내 잔존 개 재물에 의한 특성 감소를 최소화 하였다. Electro slag remelting 공법은 황(Sulfides)와 인(Phosphides)을 정련하는데 효과적이라고 알려져 있으며 추후 실시한 Vacuum arc remelting을 통해 산소
Table 2. Details of step heat-treatment group, name and status.

\begin{tabular}{|c|c|c|c|c|}
\hline Name & Normalizing & $\begin{array}{c}\text { Stress } \\
\text { Relieving }\end{array}$ & $\begin{array}{l}\text { Solution } \\
\text { Treatment }\end{array}$ & Aging \\
\hline No.1 & \multirow{4}{*}{$\begin{array}{c}1100^{\circ} \mathrm{C} / 1 \mathrm{hr} \\
\mathrm{AC}\end{array}$} & \multirow{4}{*}{$\begin{array}{c}677^{\circ} \mathrm{C} / 1 \mathrm{hr} \\
\mathrm{AC}\end{array}$} & $\begin{array}{c}1050^{\circ} \mathrm{C} / 1 \mathrm{hr} \\
\mathrm{OQ}\end{array}$ & $\begin{array}{c}490^{\circ} \mathrm{C} / 5 \mathrm{hr} \\
\mathrm{AC}\end{array}$ \\
\hline No. 2 & & & $\begin{array}{c}1000^{\circ} \mathrm{C} / 1 \mathrm{hr} \\
\mathrm{OQ}\end{array}$ & $\begin{array}{c}490^{\circ} \mathrm{C} / 5 \mathrm{hr} \\
\mathrm{AC}\end{array}$ \\
\hline No. 3 & & & $\begin{array}{l}950^{\circ} \mathrm{C} / 1 \mathrm{hr} \\
\mathrm{OQ}\end{array}$ & $\begin{array}{c}490^{\circ} \mathrm{C} / 5 \mathrm{hr} \\
\mathrm{AC}\end{array}$ \\
\hline No.4 & & & $\begin{array}{c}900^{\circ} \mathrm{C} / 1 \mathrm{hr} \\
\mathrm{OQ}\end{array}$ & $\begin{array}{c}490^{\circ} \mathrm{C} / 5 \mathrm{hr} \\
\mathrm{AC}\end{array}$ \\
\hline No.5 & \multirow{3}{*}{$\begin{array}{c}1000^{\circ} \mathrm{C} / 1 \mathrm{hr} \\
\mathrm{AC}\end{array}$} & \multirow{3}{*}{$\begin{array}{c}677^{\circ} \mathrm{C} / 1 \mathrm{hr} \\
\mathrm{AC}\end{array}$} & $\begin{array}{c}1000^{\circ} \mathrm{C} / 1 \mathrm{hr} \\
\mathrm{OQ}\end{array}$ & $\begin{array}{c}490^{\circ} \mathrm{C} / 5 \mathrm{hr} \\
\mathrm{AC}\end{array}$ \\
\hline No.6 & & & $\begin{array}{l}950^{\circ} \mathrm{C} / 1 \mathrm{hr} \\
\mathrm{OQ}\end{array}$ & $\begin{array}{c}490^{\circ} \mathrm{C} / 5 \mathrm{hr} \\
\mathrm{AC}\end{array}$ \\
\hline No.7 & & & $\begin{array}{c}900^{\circ} \mathrm{C} / 1 \mathrm{hr} \\
\mathrm{OQ}\end{array}$ & $\begin{array}{c}490^{\circ} \mathrm{C} / 5 \mathrm{hr} \\
\mathrm{AC}\end{array}$ \\
\hline \multicolumn{2}{|c|}{ Abbreviation } & \multicolumn{3}{|c|}{$\begin{array}{l}\text { H.T; Heat Treatment, Nol.; Normalizing, } \\
\text { S.R; Stress Relieving, } \\
\text { S.T.; Solution Treatment, A.C.;Air } \\
\text { Cooling, O.Q.;Oil Quenching }\end{array}$} \\
\hline
\end{tabular}

(Oxides), 질소(Nitrogen)를 제어하고자 하였다. 이러한 고청정 재용해법은 반복 열처리시 입계에 석출할 수 있는 합금원소을 제어함으로써 인성 저하 원소들을 최소화 할 수 있었다. 본 합 금조성은 철이 기지금속으로 $\mathrm{Co}$ 를 최대 첨가원소로 하는 합금이 며 열처리와 같은 후처리 공정을 통하여 첨가원소의 미세 탄화 석출상에 의하여 강성을 부가하는 전형적인 2 차경화형 재료라고

Table 1. Chemical composition of material used.

\begin{tabular}{ccccccccccc}
\hline Elements & $\mathrm{C}$ & $\mathrm{Co}$ & $\mathrm{W}$ & $\mathrm{V}$ & $\mathrm{La}$ & $\mathrm{Cr}$ & $\mathrm{Ni}$ & $\mathrm{Al}$ & $\mathrm{P}$ & $\mathrm{Fe}$ \\
\hline $\begin{array}{c}\text { Composition } \\
\text { (wt\%) }\end{array}$ & 0.24 & 13 & 3 & 0.01 & $<0.01$ & 2.5 & 10.00 & 0.01 & 0.004 & Blance \\
\hline
\end{tabular}

Table 3. Details of repeat heat-treatment group, name and status.

\begin{tabular}{|c|c|c|}
\hline Group & Name & Heat-treatment status (details) \\
\hline \multirow{3}{*}{ Basic H.T. } & No.8 & As-Received \\
\hline & No.9 & Nor. $\left(1000^{\circ} \mathrm{C} / 1 \mathrm{hr}, \mathrm{AC}\right)$ \\
\hline & No.10 & Nor. $\left(1000^{\circ} \mathrm{C} / 1 \mathrm{hr}, \mathrm{AC}\right) \rightarrow$ S.R. $\left(677^{\circ} \mathrm{C} / 1 \mathrm{hr}, \mathrm{AC}\right)$ \\
\hline \multirow{3}{*}{$\begin{array}{c}\text { Repeat S.T. } \\
\text { (1time to } \\
\text { 3times) }\end{array}$} & No.11 & $\operatorname{Nor}\left(1000^{\circ} \mathrm{C} / 1 \mathrm{hr}, \mathrm{AC}\right) \rightarrow$ S.R. $\left(677^{\circ} \mathrm{C} / 1 \mathrm{hr}, \mathrm{AC}\right) \rightarrow$ S.T. $\left(900^{\circ} \mathrm{C} / 1 \mathrm{hr}, \mathrm{OQ}\right)$ \\
\hline & No.12 & Nor $\left(1000^{\circ} \mathrm{C} / 1 \mathrm{hr}, \mathrm{AC}\right) \rightarrow$ S.R. $\left(677^{\circ} \mathrm{C} / 1 \mathrm{hr}, \mathrm{AC}\right) \rightarrow$ S.T. $\left(900^{\circ} \mathrm{C} / 1 \mathrm{hr}, \mathrm{OQ}\right) \rightarrow$ S.T. $\left(900^{\circ} \mathrm{C} / 30 \mathrm{~min}\right.$ OQ $)$ \\
\hline & No.13 & $\begin{array}{l}\text { Nor }\left(1000^{\circ} \mathrm{C} / 1 \mathrm{hr}, \mathrm{AC}\right) \rightarrow \text { S.R. }\left(677^{\circ} \mathrm{C} / 1 \mathrm{hr}, \mathrm{AC}\right) \rightarrow \text { S.T. }\left(900^{\circ} \mathrm{C} / 1 \mathrm{hr}, \mathrm{OQ}\right) \rightarrow \text { S.T. }\left(900^{\circ} \mathrm{C} / 30 \mathrm{~min} \text { OQ }\right) \\
\rightarrow \text { S.T. }\left(900^{\circ} \mathrm{C} / 30 \mathrm{~min} \text { OQ }\right)\end{array}$ \\
\hline \multirow{2}{*}{ Aging } & No.14 & Nor. $\rightarrow$ S.R. $\rightarrow$ S.T. $\rightarrow$ S.T. $\rightarrow$ S.T. (No.6 state) $\rightarrow$ Aging $\left(482^{\circ} \mathrm{C} / 5 \mathrm{hr} \mathrm{AC}\right)$ \\
\hline & No.15 & Nor. $\rightarrow$ S.R. $\rightarrow$ S.T. $\rightarrow$ S.T. $\rightarrow$ S.T. (No.6 state $) \rightarrow$ Aging $\left(500^{\circ} \mathrm{C} / 5 \mathrm{hr}\right.$ AC) \\
\hline \multicolumn{2}{|c|}{ Ethching solution } & Ethyl alcohol(95\%) $80 \mathrm{ml}$, Hydrochloric acid(HCl) $10 \mathrm{ml}$, Nitric acid (HNO3) $15 \mathrm{ml}$, Acetic acid 2 3 drop \\
\hline
\end{tabular}


할 수 있다. 열처리는 다단 열처리공정으로 normalizing, stress relieving, solution treatment, aging 순으로 진행하였다. 우선 Normalizing 및 Solution treatment 온도의 영향을 살펴보기 위하여 상기 기재한 열처리공정을 단계별로 실시하였으며, 자세 한 열처리 조건을 Table 2에 나타내었다. 또한 용체화처리를 1회부터 3회까지 반복적 열처리를 실시하여 Packet-boundary effect를 살펴보았다. 각각의 열처리와 반복적 열처리에 대한 영향을 살펴보기 위하여 다양한 조건으로 실험을 진행하였으며, 그에 대한 세부열처리 내용을 Table 3에 나타내었다.

\section{2 미세조직 및 상변화 관찰}

반복 용체화 열처리된 시편에 대하여 에칭을 실시하고 미세 조직검사를 실시하였다. 조직관찰을 위한 부식액은 Table 3에 나타내었다. 에칭된 단면시편에 대하여 광학현미경과 주사전자 현미경을 이용하여 미세조직을 관찰하였으며, 부식에 의해 나타 난 광학현미경 관찰사진의 입계에 대하여 상분석을 수행하였다. 이미지분석을 위하여 $1 \mathrm{~mm}^{2}$ 의 면적에서 다양한 형태로 나타난 입계의 평균 직경 및 $1 \mathrm{~mm}^{2}$ 내의 결정립의 수를 Wina tech사 의 BMI plus 이미징 툴을 이용하여 계산하였으며 이를 다시 ASTM E112 입도측정규격에 맞춰서 표준화하였다. 또한 반복 적 용체화 처리 시 조직 내에 잔류 오스테나이트를 측정하기 위하여 X선 응력측정기를 이용하여 상분석을 실시하였고, 오스 테나이트 분율 분석의 신뢰성을 더하기 위하여 $\mathrm{EBSD}$ 분석결과 도 병행하여 진행하였다.

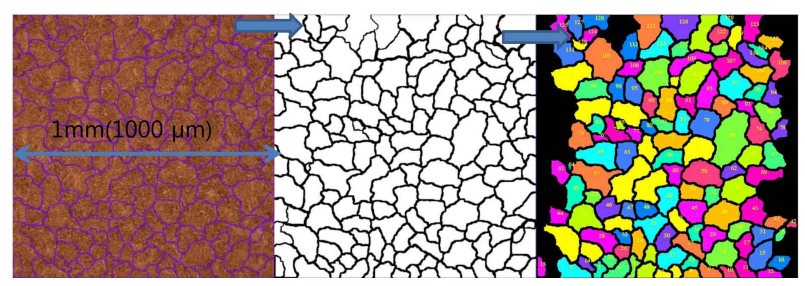

Fig. 1. The Procedure of image analyzing for calculating grain boundary using BMI plus, computer software.

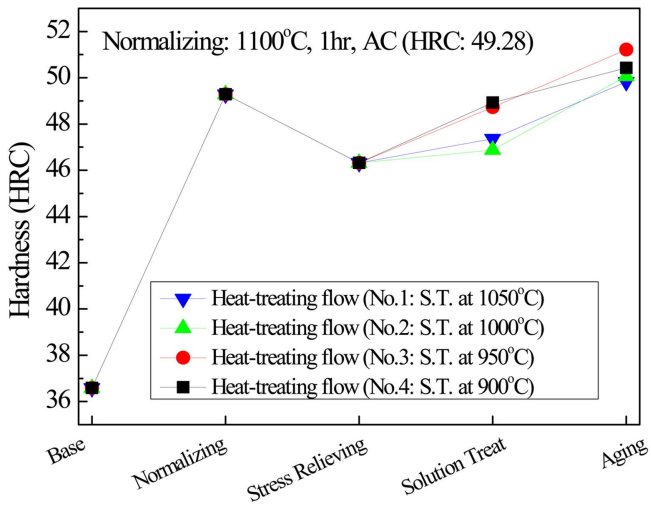

\section{3. 실험결과 및 고찰}

전체 열처리 공정은 노말라이징, 잔류응력제거, 용체화, 시효처 리 순을 진행하였으며, Fig. 2에 경도변화를 나타내었다. 본 단 계별 열처리 시 노말라이징 온도를 $1100^{\circ} \mathrm{C}, 1000^{\circ} \mathrm{C}$ 로 나누어 열처리를 실시하고 공냉처리 한 시편의 경도는 각각 49.28 (Fig. 2a)과 48.64HRC (Fig. 2b)의 평균경도를 나타내어 $1100^{\circ} \mathrm{C}$ 에서 약간 높은 경도값을 나타내었으나 차이는 크지 않았다. 본 2 종 의 노말라이징 처리된 시편은 $677^{\circ} \mathrm{C}$ 에서 1 시간 열처리 후 공 냉을 통해 잔류응력제거를 실시한 후 각기 다른 온도에서 용 체화 처리를 실시한 후 시효처리 시 경도를 비교 하였다(상세 열처리조건은 Table 2참조). 2종의 노말라이징 시편은 모두 잔 류응력제거 열처리를 통하여 경도가 약 $46 \mathrm{HRC}$ 정도로 감소하 였으며, 용체화 처리 및 시효처리를 거치면서 증가하는 현상을 나타내었다. 본 시편은 2 차경화형 시편으로서 시효처리 이후 경도비교를 통해 강성 부여를 위한 열처리 효율성을 유추 할 수 있다. $1100^{\circ} \mathrm{C}$ 에서 노말라이징 처리 한 그룹은 $950^{\circ} \mathrm{C}$ 에서 용체화 처리 한 후 시효처리 시 평균경도 $51.22 \mathrm{HRC}$ 정도로 가 장 높은 값을 나타내었으며, $1000^{\circ} \mathrm{C}$ 에서 노말라이징 처리를 한 그룹은 $900^{\circ} \mathrm{C}$ 에서 용체화 처리 시 평균경도 $52.96 \mathrm{HRC}$ 으로 가장 높은 값을 나타내었다. 본 경도실험결과를 토대로 가장 효율적인 열처리 조건으로 노말라이징 처리는 $1000^{\circ} \mathrm{C}$, 용체화 처리는 $900^{\circ} \mathrm{C}$ 로 설정 하고 반복 용체화 처리를 실시하였다.

Fig. 3에 Table 3에 따라 열처리를 진행 한 시편에 대하여 단면 광학현미경 조직을 나타내었다. 2차경화형 합금인 AsReceived 시편(No.1)을 Normalizing 처리한 후 광학현미경 조 직상에서는 관찰이 되지 않으나 입계와 입내에 강력한 탄화물 형성 원소인 $\mathrm{Co}, \mathrm{Mo}, \mathrm{W}$ 등에 의해 형성된 탄화물 $\left(\mathrm{M}_{2} \mathrm{C}\right)$ 이 형 성되었을 것으로 사료된다[2]. Nor.과 S.R.열처리를 실시한 시편 을 1회부터 3회까지 반복 용체화처리를 실시한 후 조직관찰을 (No.11 No.13) 실시한 결과 조직사진 내에서 반복적 용체화 처 리를 통하여 결정립이 확연하게 줄어드는 것을 확인 할 수 있 었다. 이는 용체화처리 이후 잔존하던 austenite는 반복적 용체

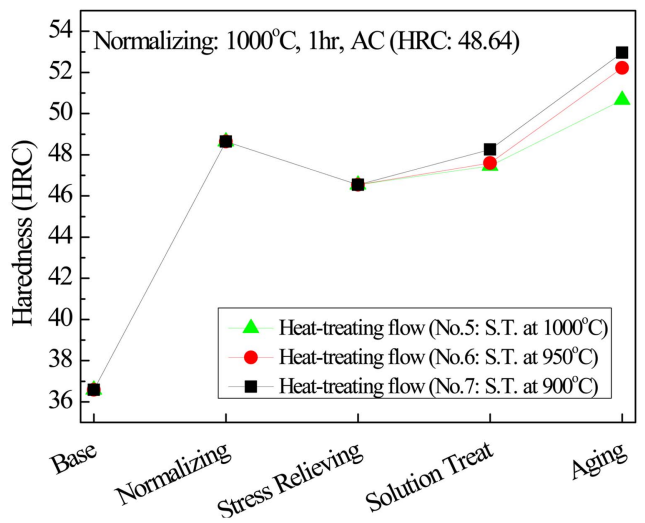

Fig. 2. A Comparison of hardness distribution according step heat-treatment (No.1 to No.7). 


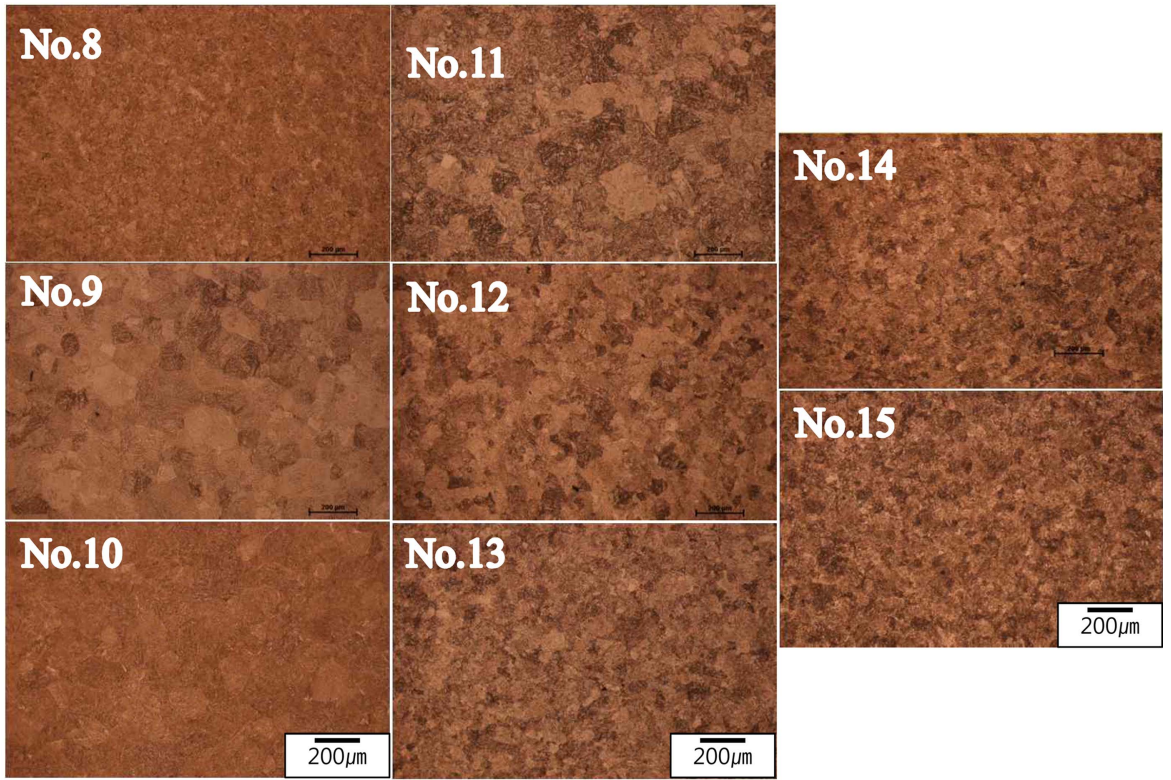

Fig. 3. Optical images of heat treated specimens, which marked number means that symbol from the Table 3.

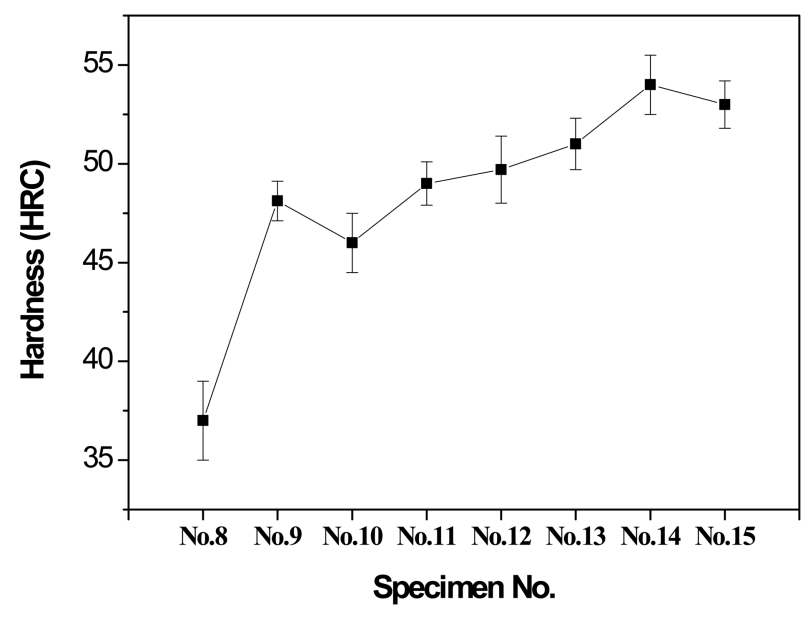

Fig. 4. Rockwell hardness analysis results which heat-treating state and its number are indicated at Table 3.(No.8 to No.15).

화 처리를 통하여 Martensite로 변태를 하게 되고 이 과정 중 에 입내에 Packet을 형성 시키며 이는 조직 내에서 결정립과 같은 거동을 나타내게 된다[8].

3 회 용체화 열처리 이후 각기 다른 온도에서 시효처리를 실 시한 조직(No.14, No.15)을 살펴보면 시효처리를 위한 유지시 간 및 온도와 상관 없이 3회 용체화 열처리한 조직과 육안상으 로 차이는 크게 나타나지 않는 것을 확인 하였다.

Table 3에 나타낸 열처리상태에 따라 경도측정을 실시하고 결과를 Fig. 4에 나타내었다. 최초 As-received 시편의 경도는 약 35 39HRC을 나타내었으며, Normalizing 처리를 통하여 약 48 49HRC로 증가하고, 이는 Stress Relieving처리를 통하
여 다시 경도가 약 44 47HRC로 낮아지는 경향을 나타내었다. No. 3 상태의 시편에 대하여 1회부터 3회까지 반복적으로 용 체화 처리를 실시하고 이에 대한 경도를 측정한 결과 경도가 1 회용체화 처리 시편인 No.11의 경도가 49 51HRC범위의 경도 값을 나타내었고, 2 3회 용체화 처리를 거치면서 경도는 서서히 증가하여 최종 3 회 용체화처리한 시편의 경도는 $52 \sim 53 \mathrm{HRC}$ 범 위의 경도를 나타내었다. 앞서 Fig. 2에 나타난 조직사진에서 언급한 바와 같이 반복적인 용체화 처리 공정에 의하여 잔존 오스테나이트의 마르텐사이트화 과정 중 입내에서 결정립으로 거동하는 또 다른 패킷이 형성되어 결정립 감소효과가 발생하 였으며, 이는 널리 알려져 있는 Hall-Petch관계식에 의거하여 Grain boundary strengthening효과에 의하여 경도가 증가된 것 으로 판단된다[9].

3 회용체화 처리 후 온도를 각각 $482^{\circ} \mathrm{C}, 500^{\circ} \mathrm{C}$ 로 5 시간동안 시효처리를 실시하고 공냉을 실시하고 본 시편에 대하여 경도 측정한 결과, 시효처리온도를 $482^{\circ} \mathrm{C}$ 로 진행한 No. 14 의 경우 $53 \sim 56$ 정도로 3 회용체화 처리시편이 가지고 있는 $52 \sim 53 \mathrm{HRC}$ 의 시편보다 증가하였다. 이는 3 회 용체화처리 동안 고용된 탄화 물이 재분배를 통한 2차경화가 발생한 것으로 판단되며, $500^{\circ} \mathrm{C}$ 에서 시효처리를 실시한 시편(No. 15)은 52 54HRC정도 로 $482^{\circ} \mathrm{C}$ (No. 9)에 비해 약간 감소한 값을 보였는데 이는 온 도증가에 따른 연화 현상으로 보여진다. 광학현미경 조직상에서 는 큰 차이가 없지만 2 차경화 현상으로 인한 경도증가는 강도 향상에 큰 이점이 있을 것으로 사료된다[10].

Fig. 1에 상분석 자료를 이용하여 반복 용체화 처리에 따른 결정립 크기를 측정 하였다. Fig. 5(a) (c)에 각각 1회, 2회, 3 회 용체화 처리조직의 이미지분석 사진과 Fig. 5(d) 반복 용 

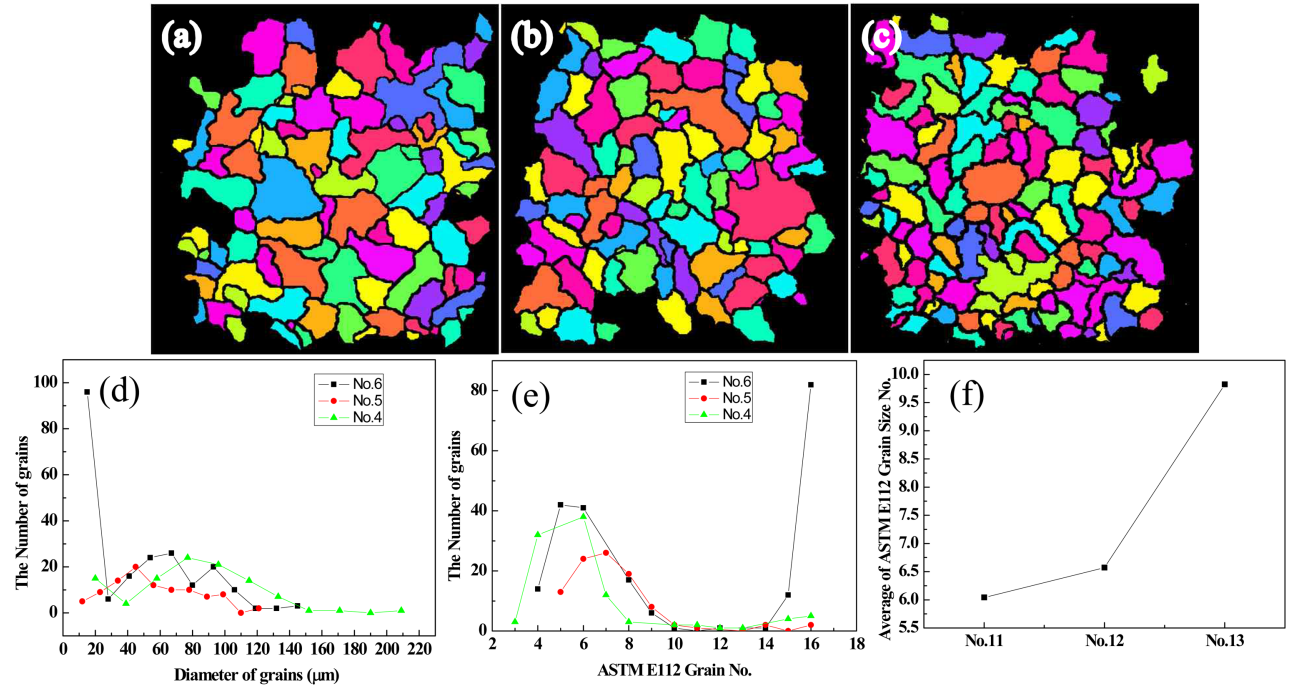

Fig. 5. Image analyzing result of cyclically solution treated specimens and calibrated ASTM E112 numbers; (a), (b), (c) Calibrated images of No.11,12 and 13, respectively. (d) Grain size distribution on No.11,12 and 13, (e) Converted by ASTM E112 numbers, (f) Comparison of average grain number of (e).

체화 처리에 따른 결정립의 크기 비교도와 이를 다시 ASTM $\mathrm{E} 112$ 규격에 따른 입도규격 변호로 환산한 결과를 Fig. 5(e)에 나타내었다. Fig. 5(a) (c) 직경 $1 \mathrm{~mm}^{2}$ 내의 결정립의 크기는 미세조직상 용체화 처리를 반복할수록 미세해 지는 것이 확인 되었으며, Fig. 5(d)에서 확인 할 수 있듯이 1회부터 3회로 용체화 처리를 반복적으로 진행 할수록 작은 입도 범위를 가 지는 결정립의 개수가 증가됨을 알 수 있었고 최종 3 회 용체 화 처리를 실시 했을 때 초기 입내에서 잔류 오스테나이트 패 킷에 의하여 형성 된 2차 결정립의 영향으로 $20 \mu \mathrm{m}$ 이내의 결 정립의 수가 현격히 증가하는 것이 확인 되었다. 이는 최초 2 회 3회를 거쳐 용체화처리를 통하여 잔류 오스테나이트 패킷이 형성 되어 2차 결정립이 형성되게 되고 또 다시 용체화처리 시 2차결정립내에 또 다른 결정립이 다시 생성된 것으로 보여 진다. Fig. 5(e)에 결정립의 크기를 ASTM E112 입도번호로 변환 하고 이에 대한 비교도를 나타내었고, 본 결과를 토대로
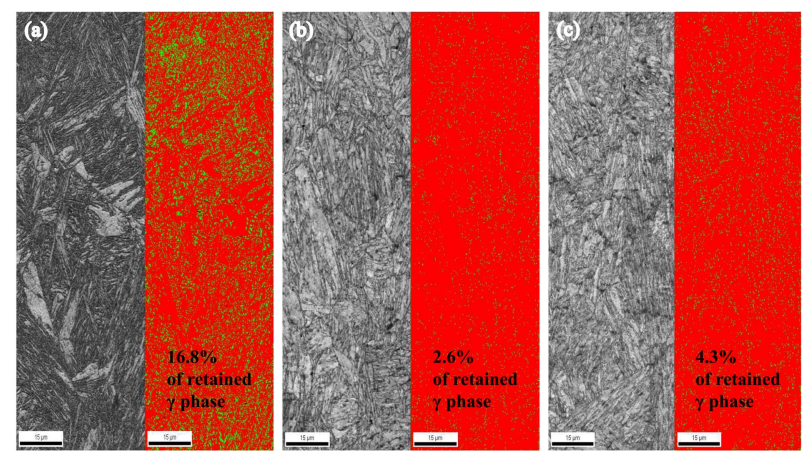

Fig. 6. The EBSD phase fraction analysis of (a)No. 8 (b) No. 13 and (c) No. 14 (red dots: martensite, green dots: austenite).
평균 ASTM E112 입도변화를 측정한 결과를 Fig. 5(f)에 도 시하였다. 1회 용체화 처리 시 ASTM E112입도번호는 6.04, 2회 용체화 처리시 $6.57,3$ 회 용체화 처리시 9.82 로 증가되는 것을 확인 하였다. 비록 결정립 크기의 입도 범위는 넓으나 ASTM E112 규격 기준 입도번호 9.82는 결정립의 직경이 약 $10 \mu \mathrm{m}$ 로 제어된 상태를 의미 하며 이는 기존 수송용기기로 사 용되는 철계 초경재의 5 8의 입도번호 범위를 상회 하는 값으 로 높은 강도가 유지될 것으로 판단되며, 본 소재와 같은 2 차 경화형 초경합금으로서 관련 연구보고에 따르면 결정립의 크기 가 작아 질수록 피로특성 및 파괴인성 증가를 나타낼 것으로 판단된다[11].

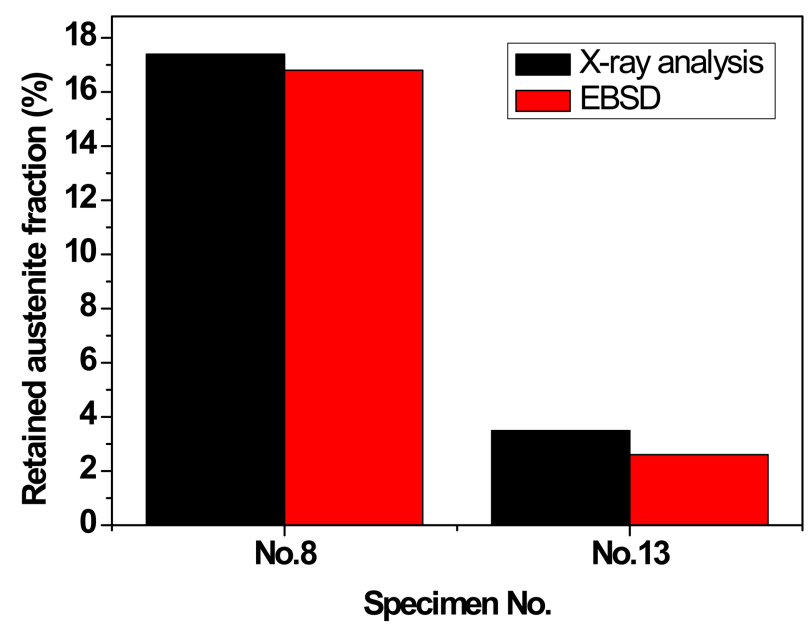

Fig. 7. Cross checking results between EBSD and X-ray stress detector about fraction of retained austenite. 
Fig. 6는 No .8, No. 13 에 대하여(Table 3의 열처리도표 참조) $\mathrm{EBSD}$ 를 이용하여 $\mathrm{SEM}$ 상 나타난 단면조직에 대하여 오스테나이트 분율을 측정한 결과를 나타내었다. 최초 No. 8시 편이 가지고 있는 $16.8 \%$ 오스테나이트 분율은 3 회 용체화처리 를 통하여 $2.6 \%$ 로 감소 하였다. 3 회 용체화 처리를 거치면서 조직 내에서 잔존 하던 오스테나이트 앞서 말한 조직내의 Packet형성을 통해 대부분 Martensite로 변태된 것으로 판단된 다. 본 상 분석결과의 신뢰성을 높이기 위하여 X-선 응력분석 기를 이용하여 같은 시편에 대하여 동일하게 상분석을 실시한 다음 EBSD결과와의 비교도를 Fig. 7에 나타내었다. X선회절 분석결과도 $\mathrm{EBSD}$ 상분석 결과와 오스테나이트 분율 변화는 비 슷하게 나타내었으나 수치가 약간 차이를 나타내었는데 이는 $1 \%$ 이하의 오차범위가 형성되어 결과가 잘 일치하는 것으로 판 단된다.

\section{4. 결 론}

1) 노말라이징 온도가 $1000^{\circ} \mathrm{C}$, 용체화처리온도가 $900^{\circ} \mathrm{C}$ 에서 열처리 한 시편의 경도가 시효처리 이후 가장 높은 경도 값을 나타내었다.

2) 반복적 용체화 처리를 위하여 결정립 크기를 이미지 분석 프로그램을 이용하여 정량적으로 측정한 결과 1 회 용체화 처리 시 ASTM E112 입도 번호 기준 6.04에서 3회 용체화 처리시 9.82로 크게 증가되었고 경도변화도 49 51HRC에서 52 53 $\mathrm{HRC}$ 로 증가하였다.

3) 시효처리 후 2 차경화효과에 의하여 3 회 용체화 처리한 시편의 경도가 52 53HRC에서 시효처리 후 53 56HRC로 증 가하였다.

4) 3 회 용체화 처리 동안의 조직내의 잔존하는 austenite의 분율은 현격히 줄어든 것을 확인 하였으며 이는 용체화 처리 를 통해서 martensite로 변태되고 조직내에서 packet을 형성 하 여 결정립 미세화 기구로 작용하였다 $(\mathrm{EBSD}$ 기준: $16.8 \% \rightarrow$ $2.6 \%)$.

5) 따라서 반복 열처리에 의한 결정립 미세화는 고강도, 고 인성 부여에 기여할 수 있을 것으로 판단된다.

\section{참고문헌}

[1] Y. Asayama: AISM, "Maraging steels recent development and application”, 47 (1988) 295 302

[2] G. Malakondaiah, M. Srinitlas and P. Rama Raot: Progress in Materials Science, "Ultrahigh-Strength low alloy steels with enhanced fracture toughnes", 42 (1997) 209 242

[3] Raghavan Ayer, Machmeier: J. Metall. Trans. A, "Transmission electron microscopy examination of hardening and toughening phenomena in Aermet100", 24A (1993) 1943 1993

[4] J. P. Campbell, K. T. Venkateswara Rao, and R. O. Ritchie: Metal. and Mat. trans. A, "The Effect of Microstructure on Fracture Toughness and Fatigue Crack Growth Behavior in $\gamma-$ Titanium Aluminide Based Intermetallics", 30A (1999) 563 577

[5] M. J. Yokota, G. Y. Lai : J. Metall. trans. A, "Toughness of Lath vs Plate Martensites", 6A (1975) 1975 1835

[6] Liu Y. j., Li Y. M., Tan Y. H. and Huang B. Y.: Inter. J. Iron and Steel Research "Apparent Morphologies and Nature of Packet Martensite in High Carbon Steels", 13 (2006) 40 46

[7] James F. Shackelford : Pearson education inc., 6th edition, "Introduction to materials science for engineerings" Chap. 6 (2005) 186 285

[8] S. Morito, M. Saito, T.Ogawa, T.Furuhara and T.Maki : ISIJ Inter, "Effect of austenite grain size on morphology and crystallography of lath martensite in low carbon steels", 45(1) (2005) 91 94

[9] W. D. Callister : 2nd ed. Wiley \& Sons, "Fundamentals of Materials Science and Engineering", 32 (2006) 252 257

[10] Zhao, Z, Zhong, B J.: Aeronaut. Mater. China, "A Study of the Mechanism of Overage Behavior in a Secondary Hardening Steel", 8(2) (1988) 8 13

[11] H. Kwon, C. M. Kim, K. B. Lee, H. R. Yang, and J. H. Lee : J. Metall. Trans. A, "Effects of $\mathrm{Co}$ and $\mathrm{Ni}$ on Secondary Hardening and Fracture Behavior of Martensitic Steels Bearing W and Cr", 29A (1998) 397 401 